Virginia Commonwealth University vCU Scholars Compass

\title{
Rape and Posttraumatic Stress Disorder (PTSD): Examining the Mediating Role of Explicit Sex- Power Beliefs for Men Versus Women
}

\section{Daniel J. Snipes}

Virginia Commonwealth University, snipesd@vcu.edu

Jenna M. Calton

Virginia Commonwealth University

Brooke A. Green

Virginia Commonwealth University

Paul B. Perrin

Virginia Commonwealth University

Eric G. Benotsch

Virginia Commonwealth University

Follow this and additional works at: http://scholarscompass.vcu.edu/psyc_pubs

Part of the Psychology Commons

(C) The Author(s) 2015

\section{Downloaded from}

http://scholarscompass.vcu.edu/psyc_pubs/38

This Article is brought to you for free and open access by the Dept. of Psychology at VCU Scholars Compass. It has been accepted for inclusion in Psychology Publications by an authorized administrator of VCU Scholars Compass. For more information, please contact libcompass@vcu.edu. 
Rape and Posttraumatic Stress Disorder (PTSD): Examining the Mediating Role of Explicit SexPower Beliefs for Men Versus Women
Journal of Interpersonal Violence 2017, Vol. 32(I6) 2453-2470

(C) The Author(s) 2015

Reprints and permissions: sagepub.com/journalsPermissions.nav DOI: I0.1I77/08862605I55926I8 journals.sagepub.com/home/jiv

(S)AGE

\title{
Daniel J. Snipes, MS,' Jenna M. Calton, MA, ${ }^{2}$ Brooke A. Green, MS,' Paul B. Perrin, PhD,' and Eric G. Benotsch, PhD'
}

\begin{abstract}
Many rape survivors exhibit symptoms of post-traumatic stress disorder (PTSD), and recent literature suggests survivors' beliefs about sex and control may affect PTSD symptoms. The present study examined beliefs about sex and power as potential mediators of the relationship between rape and PTSD symptoms for men versus women. Participants $(N=782)$ reported lifetime history of rape, current PTSD symptoms, and beliefs about sex and power. Women reported higher levels of lifetime history of rape than men (19.7\% for women; $9.7 \%$ for men). While rape history predicted PTSD symptoms for both genders, beliefs about sex and power were shown to be a significant partial mediator of this relationship for men, but not for women. Results extend the literature on rape and PTSD by suggesting that survivors' beliefs about sex and power are connected and can affect their PTSD symptoms. Additionally, results illustrate how sexual violence against
\end{abstract}

\footnotetext{
IVirginia Commonwealth University, Richmond, VA, USA

${ }^{2}$ George Mason University, Fairfax, VA, USA
}

\section{Corresponding Author:}

Daniel J. Snipes, Virginia Commonwealth University, 806 W. Franklin St., Richmond, VA 23284, USA.

Email: snipesd@vcu.edu 
men may reaffirm male gender roles that entail power and aggression, and ultimately affect trauma recovery.

\section{Keywords}

sexual abuse, male victims, sexual assault, adult victims, PTSD

\section{Introduction}

The frequency and consistency of rape in the United States is a point of concern. One in 36 college women experience an attempted or completed rape each academic year (Fisher, Cullen, \& Turner, 2000). Gender must also be considered, as male college students are also at risk of being sexually victimized: Estimates of past-year sexual assault (including experiences such as attempted unwanted sexual touching, sexual coercion via verbal arguments, and rape) against college men range from $18.5 \%$ to $31 \%$ (Larimer, Lydum, Anderson, \& Turner, 1999; O’Sullivan, Byers, \& Finkelman, 1998; Palmer, McMahon, Rounsaville, \& Ball, 2010).

\section{Gender, Rape, Cognition, and Posttraumatic Stress Disorder (PTSD)}

Like other traumatic events, the experience of a rape is a risk factor for the development of PTSD. According to the Diagnostic and Statistical Manual of Mental Disorders (5th ed.; DSM-5; American Psychiatric Association, 2013), PTSD is characterized by intrusive symptoms (flashbacks of the events), avoidance behaviors (avoiding people or situations that remind the survivor of their rape), negative alterations in cognitions or affect (e.g., cognitions that the world is unsafe place), and hyper-arousal (e.g., being easily startled). PTSD is a common problem following sexual trauma and rape. Moreover, rape trauma is unique in that it can be more traumatic than other types of trauma; both men and women who indicate their rape as their most significant trauma are more likely to develop PTSD than survivors of other traumas (Kessler, Sonnega, Bromet, Hughes, \& Nelson, 1995). When examining PTSD and gender in the context of rape, women have a higher risk of developing PTSD than men (Tolin \& Foa, 2006), but men are generally less likely to disclose being raped (Mezey \& King, 2000), which can have serious consequences for the treatment of any PTSD symptoms that may arise.

To develop more effective treatments for PTSD, researchers have begun to examine the personal beliefs and experiences that affect survivors' recovery 
from trauma (Baugher, Elhai, Monroe, \& Gray, 2010). Research has suggested that male rape survivors' feelings and beliefs about rape can affect their recovery (Davies, Walker, Archer, \& Pollard, 2010). Given that men may cope with the effects of rape in different ways than women (Holmes, Offen, \& Waller, 1997), it is important to examine the differences in belief systems among male and female rape survivors. Indeed, male rape survivors may struggle with the concept of being both a man and a survivor of rape (Artime, McCallum, \& Peterson, 2014).

\section{Distorted Cognitions and Beliefs About Sex and Power}

Many theories of trauma suggest that traumatic events can affect the survivors' thoughts and beliefs, which affect their emotional response to trauma (E. B. Foa, Ehlers, Clark, Tolin, \& Orsillo, 1999; Jaycox, Zoellner, \& Foa, 2002). In other words, rape victims may develop distorted or maladaptive cognitions, which are beliefs that would not be validated by others (e.g., I'm weak because I allowed myself to be raped) and that cause the individual distress (Kovacs \& Beck, 1978). Epstein (1991) proposed four beliefs that change following a traumatic experience: the belief that people are trustworthy, the idea that oneself is worthy, the belief that the world is safe, and the belief that the world has meaning.

Other researchers have simplified the types of distorted cognitions that can lead to PTSD. For instance, emotional processing theory has been useful in examining the role of distorted cognitions in the development and maintenance of PTSD (E. B. Foa \& Kozak, 1986; E. B. Foa, Steketee, \& Rothbaum, 1989). In this model, two distorted cognitions are proposed as an outcome of rape: the belief that the world is dangerous and the belief that one is incompetent. These cognitions are thought to meditate the relation between rape trauma and PTSD development, such that sexual trauma leads to distorted cognitions, which in turn lead to PTSD symptoms (E. B. Foa \& Rothbaum, 1998) primarily via avoidance behaviors (Ehlers \& Clark, 2000). To this point, E. B. Foa et al. (1999) found that those with distorted cognitions exhibited higher levels of PTSD symptoms than their traumatized counterparts with healthier cognitions. In another study, Iverson, King, Cunningham, and Resick (2015) found that individuals who exhibited an increase in raperelated cognitive distortions were more likely to experience an increase in PTSD symptoms and that their cognitive distortions treated in therapy resulted in reduced symptoms of PTSD approximately 5 to 10 years after treatment. What is missing from the aforementioned studies, and other research on cognitive distortions, are examinations of a broader understanding of distorted cognitions as they pertain to dominance and power. Thus, in 
this article, we explore the potential for distorted cognitions to manifest as unhealthy beliefs about power and sex. Given the impact of distorted cognitions on PTSD in rape-PTSD frameworks, it is probable that unhealthy beliefs pertaining to power and sex may serve as a distorted cognition, which may further complicate recovery from rape.

\section{Rape and Beliefs About Sex and Power}

One category of distorted cognitions may be the belief that engaging in sex inherently requires dominance of one partner and submission of the other (Zurbriggen, 2000), especially in individuals who experienced helplessness during their sexual assault. Individuals may come to the conclusion that some resistance to sexual advances is inherent in the nature of sex and is something to overcome via dominance and control (Chapleau \& Oswald, 2010). Indeed, beliefs that conflate power and sex have been associated with sexual aggression (Zurbriggen, 2000) and can be conceptualized as a form of rape myth acceptance (Chapleau \& Oswald, 2010). Men and women have different ways of coping with sexual trauma (Mezey \& King, 2000), which can manifest as different distorted cognitions that lead to PTSD. Gender differences often arise in rape-related beliefs, given that men tend to endorse rape myths to a higher degree than women (Chapleau \& Oswald, 2010; Reilly, Lott, Caldwell, \& DeLuca, 1992; Rosenthal, Levy, \& Earnshaw, 2012), and the male gender role encourages sexual prowess, domination, and callousness (Graham, 2006).

\section{Present Study}

The present study examined the theoretical influence of explicit power-sex beliefs on PTSD symptoms in a sample of college students. In line with emotional processing theory, we conceptualized explicit power-sex beliefs as distorted cognitions, which may be associated with PTSD symptoms. Given the nature of power-sex beliefs, and the myriad gender differences in sex-related beliefs, we evaluated this model as a function of gender. Although women are at an increased risk of developing PTSD in general, we predicted that the relationship between rape-related PTSD and power-sex beliefs would be stronger for males for three reasons: (a) males are more likely to endorse rape myths (Chapleau \& Oswald, 2010; Reilly et al., 1992), (b) males have lower rates of sexual abuse disclosure (Mezey \& King, 2000), and (c) males experience the stigma associated with being male rape survivors (Artime et al., 2014). In summary, these factors may exacerbate the relationship between distorted cognitions (e.g., power-sex beliefs) and PTSD symptoms. 


\section{Method}

\section{Participants}

Participants' $(n=782)$ ages ranged from 18 to 48 years $(M=19.27, S D=$ 2.80 ). Of these participants, $68.3 \%$ were female and $31.7 \%$ were male, and $51.0 \%$ identified as White, $23.0 \%$ identified as African American, $11.6 \%$ identified as Asian American, 7.4\% identified as other, 6.5\% identified as Hispanic, and $0.4 \%$ identified as Native American. Of these participants, $94.2 \%$ identified as heterosexual, 3.1\% identified as bisexual, $2.0 \%$ identified as homosexual, and $0.6 \%$ identified as queer. In addition, the majority of participants reported being in their first year of college (65.6\%), although $17.8 \%$ reported being in their second year, $10.7 \%$ reported being in their third year, $4.1 \%$ reported being in their fourth year, and $1.8 \%$ reported being in their fifth year.

\section{Procedure}

Participants were undergraduate students from a university in the southeastern United States who completed an online survey for course credit. Participants were given the option to complete an additional assignment if they did not want to participate. Informed consent was collected before the survey was administered. As the survey contained questions about rape and substance use, participants were given information about university counseling services that they could contact if they needed professional help. Participant data were kept anonymous. All study procedures were approved by the university's institutional review board.

\section{Measures}

Rape. Sexual victimization was measured using Testa et al.'s (2010) revised version of the Sexual Experiences Survey (RSES; Koss et al., 1987; Testa VanZile-Tamsen, Livingston, \& Koss, 2004), which measures five outcomes of sexual victimization (unwanted touching, attempted sexual assault, and penetrative sexual assault [anal, oral, or sexual intercourse]). It also assesses four tactics used by perpetrators: coercion, threats of physical harm, physical force, and incapacitation. As the main focus of this study was on rape, we only retained questions from the RSES which examined penetrative sexual assault resulting from threats of physical harm, physical force, or incapacitation; we did not perform analyses on unwanted touching, attempted sexual assault, or sexual assault as a result of verbal coercion.

PTSD CheckList-Civilian Version (PCL-C). Participants completed the PCL-C, which measures PTSD symptoms, as described in the Diagnostic 
and Statistical Manual of Mental Disorders (4th ed.; DSM-IV; American Psychiatric Association, 1994), in civilian populations (Weathers et al., 1991, 1993). The PCL-C consists of 17 items that correspond to the three clusters of PTSD symptoms specified in the DSM-IV: re-experiencing the trauma (Cluster B; for example, "Feeling very upset when something reminded you of a stressful experience from the past"), avoidance/numbing (Cluster C; for example, "Feeling distant or cut off from other people?"), and arousal (Cluster D; for example, "Feeling jumpy or easily startled?"). Participants responded to each item using a 5-point Likert-type scale ranging from 1 (not at all) to 5 (extremely) to indicate how much they had been bothered by each symptom in the past month. PCL-C responses can be scored in two ways. The cutoff score method maintains that PCL-C total scores greater than 50 suggest a respondent meets criteria for a PTSD diagnosis. The symptom cluster method maintains that a symptom item rating of moderately or higher (i.e., a score of 3 or more) constitutes endorsement of that symptom. Respondents meet criteria for a diagnosis of PTSD if they endorse one or more Cluster B items, three or more Cluster C items, and two or more Cluster D items. PCL-C has demonstrated Cronbach's alpha of .97, a test-retest reliability of .96, and convergent validity with other PTSD scales, such as the Mississippi Scale (.93) and the Minnesota Multiphasic Personality Inventory-2 (MMPI-2) Keane PTSD (PK) Scale (.77; Weathers et al., 1993). In the present sample, Cronbach's alpha was .92 , indicating strong internal consistency reliability.

Explicit Power-Sex Measure. Participants completed the Explicit Power-Sex Measure, which measures the belief that sex and power are linked (Chapleau \& Oswald, 2010). The Explicit Power-Sex Measure consists of 11 items, including "During sex, one person is typically 'in charge' of the other" and "During sex, one person should be dominant and the other should be submissive." Items on this measure are phrased so that participants can respond from the perspective of being dominant or submissive. Participants rated their agreement with each statement using a 5-point Likert-type scale ranging from 1 (not at all agree) to 7 (very much agree). Total scores are created by calculating the mean, with higher scores indicating more agreement with explicit power-sex beliefs. Chapleau and Oswald (2010) obtained a Cronbach's alpha of .83. In the present sample, Cronbach's alpha was .90, indicating strong internal consistency reliability.

\section{Data Analysis Plan}

Student's $t$ tests were used to examine mean-level differences in PTSD and explicit power-sex beliefs between men and women. Pearson's $r$ correlations 
Table I. Univariate Differences Between Men and Women.

\begin{tabular}{|c|c|c|c|}
\hline & Men $(n=248)$ & Women $(n=534)$ & \\
\hline & $M(S D)$ & $M(S D)$ & $t$ \\
\hline PTSD symptoms & $33.00(12.52)$ & 34.85 (12.69) & $-1.91 t$ \\
\hline Re-experiencing & $09.31(4.35)$ & $10.87(4.76)$ & $-4.38 * *$ \\
\hline Avoidance & $13.34(5.61)$ & I $3.55(5.5 \mid)$ & -0.50 \\
\hline Arousal & $10.35(4.05)$ & $10.43(3.97)$ & -0.27 \\
\hline Explicit sexual power & $21.17(11.15)$ & $19.23(9.27)$ & $2.55^{*}$ \\
\hline
\end{tabular}

Note. PTSD $=$ posttraumatic stress disorder. $t_{p}<.10 . * p<.05 . * * p<.001$.

separated by gender were performed to examine differential relations between rape, explicit power-sex beliefs, and PTSD symptoms. Hayes' (2013) PROCESS was used to examine the mediating role of explicit power-sex beliefs on the relation between rape and PTSD symptoms. Gender was added as a moderator of the relation between both rape and explicit power-sex beliefs, and explicit power-sex beliefs and PTSD symptoms. The moderated mediation was tested using bootstrapping ( $n=1,000$ samples) confidence intervals (CIs; Hayes, 2013). To help clarify the nature of the interactions provided, we ran post hoc PROCESS models to illustrate the different mediational pathways for men and women. Two-tailed tests at an alpha level of .05 were used for each analysis performed.

\section{Results}

\section{Sex Differences}

A considerable number of participants reported a history of rape $(16.5 \%$ overall; $9.7 \%$ for Men; $19.7 \%$ for Women). Univariate differences between men and women in PTSD symptoms and explicit power-sex beliefs are shown in Table 1: Men had generally higher explicit power-sex beliefs than women; Women had greater re-experiencing PTSD symptoms than men. There were no observed gender differences in PTSD-related arousal and avoidance; composite PTSD scores were marginally lower for men compared with women. For males, history of rape was associated with explicit powersex beliefs, $r(248)=.271, p<.001$, and PTSD symptoms, $r(248)=.265, p<$ .001 . PTSD symptoms were also significantly correlated with power-sex beliefs, $r(248)=.302, p<.001$. Similar patterns were also found for women, whereby history of rape was related to explicit power-sex beliefs, $r(534)=$ 


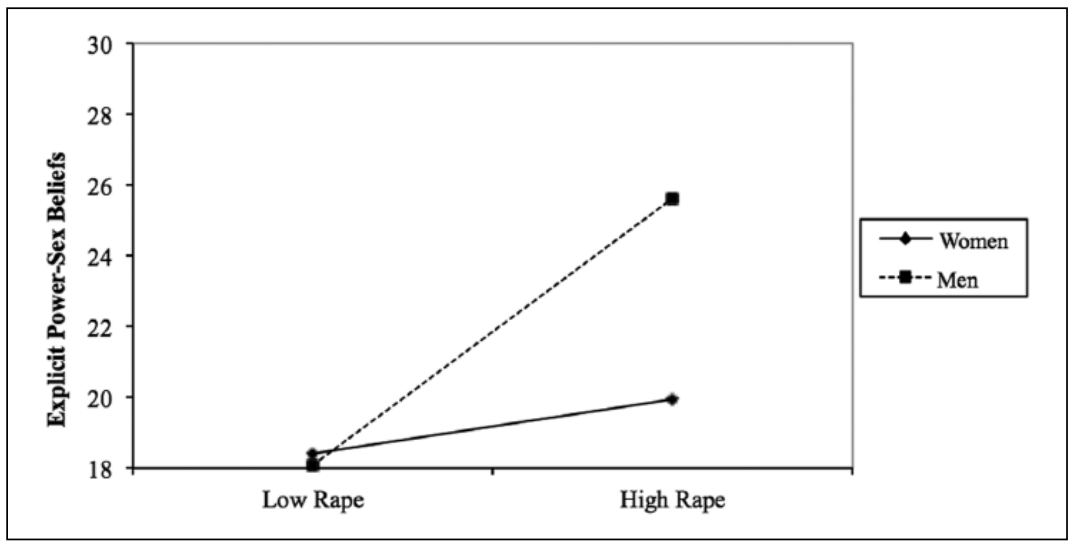

Figure I. Interaction of gender and rape on explicit power-sex beliefs.

$.09, p=.04$, and PTSD symptoms, $r(534)=.219, p<.001$. PTSD symptoms and explicit power-sex beliefs were also correlated, $r(534)=.208, p<.001$. There was general uniformity in the relationships when PTSD was broken down into individual clusters, so the decision was made to sum the subscales to create an overall measure of PTSD symptoms.

\section{Moderated Mediation Analyses}

To further emphasize the gender differences in the relation between rape and explicit power-sex beliefs, we performed moderated mediation (Hayes, 2013). The PROCESS method performs two analyses: the first considers the role of the gender, rape, and their interaction on explicit power-sex beliefs. This model was significant overall, $F(3,778)=4.64, p=.03, R^{2}=.042$. Male gender was a significant predictor of explicit power-sex beliefs, $b=2.70$, $t(778)=2.98, p=.003$. Rape was also predictive of explicit power-sex beliefs, $b=4.62, t(778)=3.23, p=.001$. The interaction of gender and rape on explicit power-sex beliefs was also significant, $b=8.16, t(778)=2.09, p$ $=.037$. Simple slopes analysis indicated that the nature of interaction was that there was a significantly stronger effect of rape on explicit power-sex beliefs for men $(\beta=.381, p<.001)$ than there was for women $(\beta=.076, p=.06)$. This interaction is outlined in Figure 1.

The second model from the PROCESS method examined the role of gender, rape, and explicit power-sex beliefs on PTSD symptoms; the interaction of gender and rape was also included. The overall model was significant, $F(4$, $777)=16.06, p<.001, R^{2}=.102$. Rape continued to predict PTSD symptoms 


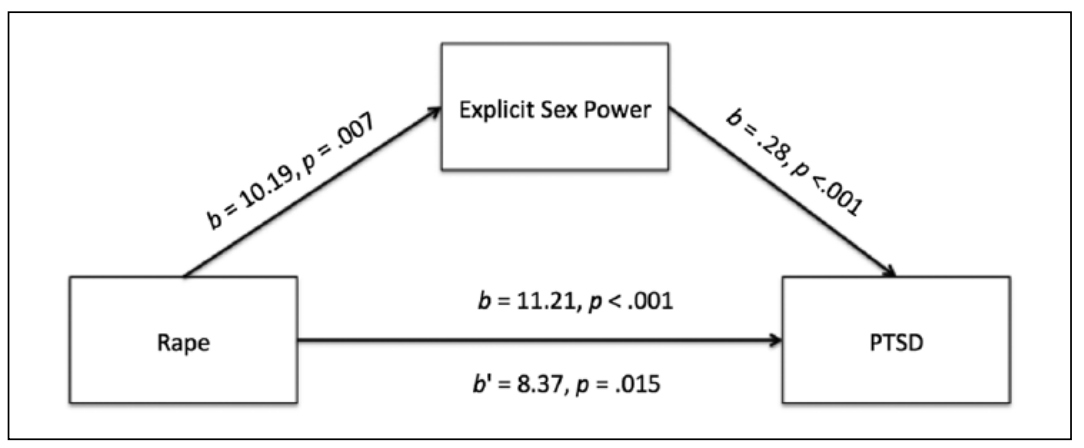

Figure 2. Mediation model for men.

after the introduction of explicit power-sex beliefs, $b=710, t(777)=4.96$, $p<.001$. Explicit power-sex beliefs also strongly predicted PTSD symptoms, $b=0.27, t(777)=4.83, p<.001$. Male gender failed to predict PTSD symptoms, $b=-1.59, t(777)=-1.59, p=.11$. The interaction of gender and rape did not predict PTSD symptoms, indicating that the relation between rape and PTSD symptoms was not different as a function of gender, $b=2.04$, $t(777)=0.57, p=.57$. The individual mediation models for men and women are displayed in Figures 2 and 3.

The conditional direct effects of rape on PTSD symptoms for both men, $b=6.45, t(777)=4.57, p<.001$, and women, $b=8.49, t(777)=2.57, p=.01$, indicated significant, positive effects; this illustrates that rape predicted PTSD symptoms significantly for both men and women. The conditional indirect effects of rape on PTSD revealed gender differences in the mediating role of explicit power-sex beliefs. For men, there was an indirect effect of rape on PTSD symptoms through explicit power-sex beliefs, $b=.68, S E=$ $1.06, \mathrm{CI}=[1.13,5.45]$. For women, there was no such indirect effect, $b=$ $-.32, S E=.36, \mathrm{CI}=[-.01,1.38]$.

\section{Discussion}

This study examined the relationship between rape victimization, explicit power-sex beliefs, and PTSD symptoms among a sample of college students. Approximately $16 \%$ of our sample reported a lifetime history of rape victimization, which is similar to other prevalence rates (15\%-20\%) obtained with college students (Brener, McMahon, Warren, \& Douglas, 1999; Fisher et al., 2000). We found a history of rape victimization was positively associated with PTSD symptoms, which is well documented in the literature (e.g., Fisher 


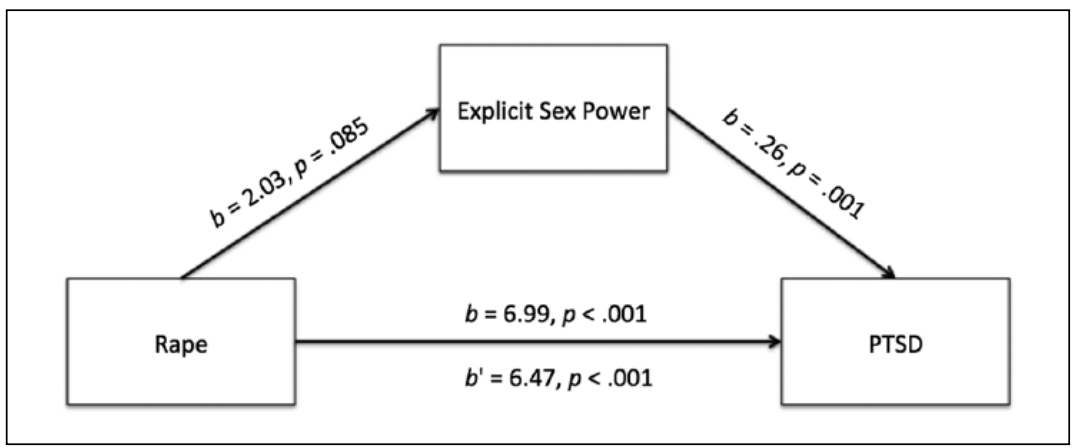

Figure 3. Mediation model for women.

et al., 2000; Solomon \& Davidson, 1997). These results are consistent with prior research that suggests sexual victimization is relatively common among college students (Fisher et al., 2000), even among men (O'Sullivan et al., 1998), and can be highly traumatic (Kessler et al., 1995).

This study expands researchers and practitioners' knowledge about the association between rape and PTSD symptoms by exploring the relationship between beliefs about sex and PTSD symptoms in a sample of college students. Results suggest that explicit power-sex beliefs (i.e., conscious beliefs that consensual sex inherently involves power) partially account for the severity of PTSD symptoms after rape. One key limitation frames our interpretation of these findings: Due to the cross-sectional nature of our data, we cannot determine whether explicit power-sex beliefs existed prior to the trauma or whether they evolved as a result of the trauma. In addition, we are unable to assess whether PTSD symptoms influence power-sex beliefs later in an individual's life. Although this is a limitation, it is also a rich source of discussion. Our findings suggest two theoretical pathways to the associations between rape, explicit power-sex beliefs, and PTSD might exist and warrant further research (see limitations section), both of which are discussed herein.

First, it is possible that some survivors associate sex with power because they were raped. A survivor might internalize the idea that sex is overtly associated with a power differential, in which case his or her responses to the Explicit Power-Sex Measure may reflect distorted thoughts about sex. For example, despite not having a preference for a power differential between partners during consensual sexual activity, a person who has been raped may begin to believe that the power differential will occur regardless of his or her preferences. This is consistent with the theory that rape can spur the development of new attitudes toward rape myth acceptance, or reifies maladaptive 
beliefs about rape (Baugher et al., 2010), as well as the idea that women who are raped may associate sex in general with their disempowering experience of assault (Zurbriggen, 2000). Conversely, some people who have been raped may have espoused high explicit power-sex beliefs prior to victimization, in which case these individuals may have had a proclivity for engaging in risky sexual behaviors that may contribute to the likelihood of sexual victimization.

Regardless of the way in which explicit power-sex beliefs develop, the current results suggest that explicit power-sex beliefs are one aspect of cognitive processes that warrant exploration in connection to survivors' PTSD symptoms. This finding is aligned with previous research that suggests that cognitive processes, such as cognitive appraisals of the trauma, affect survivors' psychological functioning (Hall, French, \& Marteau, 2003; Jaycox et al., 2002). Similarly, D. W. Foa (1992) suggests rape victims with chronic PTSD are likely to endorse cognitive distortions (i.e., exaggerated or irrational thoughts; see Beck, 2011) that the world is a dangerous place and that they are helpless and incompetent. The current results help identify one cognitive distortion that may contribute to or stem from distress: The idea that sex is about dominance and power, as opposed to sexual pleasure or love, may amplify a survivor's PTSD symptoms (e.g., avoidance of sexual activity). These cognitions are important to understand because they may contribute to resilience or to rehabilitation post trauma.

The current finding that beliefs about power and control during sex may influence the PTSD symptoms of individuals who have been raped also extends the literature on the importance of a sense of control in trauma recovery. Previous research has found that sexual assault survivors' perceptions of their control over the present and future is associated with lower levels of distress (Frazier, 2003), as well as PTSD symptoms (Jaycox et al., 2002). Similarly, perceived control over trauma recovery is related to fewer PTSD symptoms (Frazier, Steward, \& Mortensen, 2004; Najdowski \& Ullman, 2009). As such, it is possible that the more control people believe they have over their life, the less distress they experience after rape. However, the current results suggest that perceptions of power related to consensual sex (i.e., explicit power-sex beliefs) can affect PTSD symptoms, as well. The belief that one sexual partner has more power than another during sex may influence the severity of PTSD symptoms after rape.

It is also important to note that this is one of the first studies to utilize the Explicit Power-Sex Measure, and it is the first to explore explicit power-sex beliefs among a college student sample that includes rape survivors. The measure was originally created to explore the relationship between explicit power-sex beliefs and sexually aggressive attitudes and behaviors (Chapleau 
\& Oswald, 2010). The average level of explicit power-sex beliefs in the current sample was low, which is consistent with the average obtained by Chapleau and Oswald (2010). In addition, men had higher scores than women on this measure, which is also consistent with Chapleau and Oswald's findings. The fact that men reported higher levels of explicit power-sex beliefs than women is also consistent with research suggesting that men implicitly associate sex with aggression more than women (Mussweiler \& Forster, 2000).

\section{Gender Differences}

The relationships among rape, explicit power-sex beliefs, and PTSD were explored separately for men and women. For men, the effect of rape on PTSD symptoms was partially, but significantly, mediated by explicit sexual power (i.e., power-sex beliefs accounted for some, but not all, of the variance between rape and PTSD symptoms). However, for women, the effect of rape on PTSD symptoms was not significantly mediated. This suggests that women may be more likely to experience PTSD regardless of whether they think that one partner should have power over another during consensual sex, whereas men's beliefs about power during consensual sex may have a greater association with their PTSD symptoms. In addition, gender moderated the relationship between rape victimization and explicit power-sex beliefs, such that men had a much stronger relation between rape and power-sex beliefs than did women.

One reason for this gender difference may be that men espouse higher levels of explicit power-sex beliefs than women, which indicates that power and sex are more strongly connected for men. It is possible that rape victimization amplifies the beliefs that men already espouse. Alternately, if explicit power-sex beliefs among men operate such that they are socialized to think of themselves as powerful through sex, being raped may cause a greater shift in their power-related worldview than for women. Traditional male gender roles emphasize control (David \& Brannon, 1976; Pleck, 1981), so when power and control are taken away from men during sexual victimization, they might internalize that experience to a greater degree than women and then exhibit more severe PTSD symptomatology because of the extreme challenge to their worldview.

\section{Clinical Implications}

Results of this study suggest that it is possible that the way a person who has been raped thinks about the power involved in consensual sex may influence 
the relationship between rape and severity of PTSD symptoms. This finding supports the use of cognitive strategies (e.g., cognitive restructuring) to help victims explore their thoughts about power during sex and the relationship between those thoughts and their symptoms. As part of the re-experiencing nature of PTSD, symptoms may be triggered by experiences that are perceptually similar to the traumatic event (Ehlers, Hackmann, \& Michael, 2004). For rape survivors, it is possible that consensual sexual activity may trigger symptoms of PTSD, during which cognitive distortions about sex may perpetuate the anxiety associated with PTSD symptoms.

Although evidence-based forms of PTSD treatment (e.g., cognitive processing therapy; Resick, Williams, Suvak, Monson, \& Gradus, 2012) already utilize cognitive strategies with people who have been raped, the current results suggest that clinicians may consider also incorporating a focus on the meaning of consensual sexual relationships, especially relating to power. Helping people who have been raped to develop more adaptive beliefs about sex may alleviate anxiety and help them de-internalize the connection between sex and power. In addition, because the relationship between rape and PTSD is more strongly mediated by explicit power-sex beliefs for men than women, when considering PTSD treatment for men, it may be particularly important to examine power-related beliefs about sex and explore how those beliefs are affected by victimization experiences.

\section{Limitations and Future Research}

Despite these contributions, this study has several limitations, which frame directions for future research. First, this study was conducted using a sample of undergraduate students, limiting the generalizability of the findings. It should be replicated using a community sample of rape victims of all ages. Second, as previously discussed, it is impossible to determine whether participants' explicit power-sex beliefs developed or changed as a result of experiencing rape. Longitudinal research using cross-lag panel designs could help untangle the causal pathways among these variables. Furthermore, qualitative research may be particularly helpful in determining how beliefs about consensual sex are affected by trauma, because qualitative methods allow people who have been raped to describe their sexual preferences before and after victimization and reflect on the change in greater detail than quantitative measures.

Second, the current study did not assess traumatic experiences other than rape. It is possible that other traumatic experiences are influencing participants' PTSD symptoms. Future research should assess multiple types of traumatic experiences, have participants complete PTSD measures in relation to 
each trauma, and control for other traumas when running analyses. Future research should also assess the number of times a person has experienced sexual assault and the amount of time that has elapsed since the last victimization occurred. Re-victimization and time of victimization may affect both the severity of PTSD symptoms and levels of explicit power-sex beliefs. People who have experienced multiple traumas may be more likely to internalize explicit power-sex beliefs than those who have experienced one incident of victimization.

Third, our measure of rape did not include an age limit. Given that men are victimized in lower numbers than women, we opted to collect data on sexual victimization across the lifetime to increase our statistical power. This decision precluded us from showing differences between childhood sexual abuse and adult rape as well as a lack of specificity of the meaning of our rape variable. Given that our rape variable indicates any rape across the lifetime, we cannot extend our results to suggesting whether those cases were childhood sexual abuse or adult sexual abuse. Therefore, we suggest that future research utilize measures of childhood sexual abuse and adult rape to further clarify the results presented in this article.

Despite these limitations, this is the first study to explore the relationships among rape, explicit power-sex beliefs, and PTSD. Explicit power-sex beliefs were found to mediate the relationship between rape and PTSD symptoms, particularly for men, which suggest that power-related cognitions about consensual sexual activity are associated with psychological functioning in the aftermath of a sexual assault and may prove to be a promising pathway for future research on PTSD treatment.

\section{Authors' Note}

Any opinion, findings, and conclusions or recommendations expressed in this material are those of the authors and do not necessarily reflect the views of the National Science Foundation.

\section{Declaration of Conflicting Interests}

The author(s) declared no potential conflicts of interest with respect to the research, authorship, and/or publication of this article.

\section{Funding}

The author(s) disclosed receipt of the following financial support for the research, authorship, and/or publication of this article: This material is based upon work supported by the National Science Foundation Graduate Research Fellowship under Grant DGE-1147383. 


\section{References}

American Psychiatric Association. (1994). Diagnostic and statistical manual of mental disorders (4th ed.). Washington, DC: Author.

American Psychiatric Association. (2013). Diagnostic and statistical manual of mental disorders (5th ed.). Arlington, VA: American Psychiatric Publishing.

Artime, T. M., McCallum, E. B., \& Peterson, Z. D. (2014). Men's acknowledgment of their sexual victimization experiences. Psychology of Men \& Masculinity, 15, 313.

Baugher, S. N., Elhai, J. D., Monroe, J. R., \& Gray, M. J. (2010). Rape myth acceptance, sexual trauma history, and posttraumatic stress disorder. Journal of Interpersonal Violence, 25, 2036-2053.

Beck, J.S. (2011). Cognitive behavior therapy: Basics and beyond. New York, NY: The Guilford Press.

Brener, N. D., McMahon, P. M., Warren, C. W., \& Douglas, K. A. (1999). Forced sexual intercourse and associated health-risk behaviors among female college students in the United States. Journal of Consulting and Clinical Psychology, 67, 252-259.

Chapleau, K. M., \& Oswald, D. L. (2010). Power, sex, and rape myth acceptance: Testing two models of rape proclivity. Journal of Sex Research, 47, 66-78.

David, D. S., \& Brannon, R. (1976). The forty-nine percent majority: The male sex role. Reading, MA: Addison-Wesley.

Davies, M., Walker, J., Archer, J., \& Pollard, P. (2010). A comparative study of longterm psychological functioning in male survivors of stranger and acquaintance rape. Journal of Aggression, Conflict and Peace Research, 2, 25-33.

Ehlers, A., \& Clark, D. M. (2000). A cognitive model of posttraumatic stress disorder. Behaviour Research and Therapy, 38, 319-345.

Ehlers, A., Hackmann, A., \& Michael, T. (2004). Intrusive re-experiencing in posttraumatic stress disorder: Phenomenology, theory, and therapy. Memory, 12, 403-415.

Epstein, S. (1991). The self-concept, the traumatic neurosis, and the structure of personality. In D. Ozer, J. M. Healy, Jr., \& A. J. Stewart (Eds.), Perspectives in personality: A research annual (pp. 63-98). London: Jessica Kingsley.

Fisher, B. S., Cullen, F. T., \& Turner, M. G. (2000). The sexual victimization of college women series: Research report (NCJ 182369). Washington, DC: U.S. Department of Justice, Bureau of Justice Statistics and National Institute of Justice.

Foa, D. W. (1992). Treating PTSD: Cognitive-behavioral strategies. New York, NY: Guilford Press.

Foa, E. B., Ehlers, A., Clark, D. M., Tolin, D. F., \& Orsillo, S. M. (1999). The Posttraumatic Cognitions Inventory (PTCI): Development and validation. Psychological Assessment, 11, 303-314.

Foa, E. B., \& Kozak, M. J. (1986). Emotional processing of fear: Exposure to corrective information. Psychological Bulletin, 99, 20-35.

Foa, E. B., \& Rothbaum, B. O. (1998). Treating the trauma of rape: Cognitive behavioral therapy for PTSD. New York, NY: Guilford Press. 
Foa, E. B., Steketee, G., \& Rothbaum, B. O. (1989). Behavioral/cognitive conceptualizations of post-traumatic stress disorder. Behavior Therapy, 20, 155-176.

Frazier, P. A. (2003). Perceived control and distress following sexual assault: A longitudinal test of a new model. Journal of Personality and Social Psychology, 84, 1257-1269.

Frazier, P. A., Steward, J., \& Mortensen, H. (2004). Perceived control and adjustment to trauma: A comparison across events. Journal of Social and Clinical Psychology, 23, 303-324.

Graham, R. (2006). Male rape: The careful construction of the male victim. Social \& Legal Studies, 15, 187-208.

Hall, S., French, D. P., \& Marteau, T. M. (2003). Causal attributions following serious unexpected negative events: A systematic review. Journal of Social and Clinical Psychology, 22, 515-536.

Hayes, A. F. (2013). Introduction to mediation, moderation, and conditional process analysis: A regression-based approach. New York, NY: Guilford Press.

Holmes, G., Offen, L., \& Waller, G. (1997). See no evil, hear no evil, speak no evil: Why do relatively few male victims of childhood sexual abuse receive help for abuse-related issues in adulthood? Clinical Psychology Review, 17, 69-88.

Iverson, K. M., King, M. W., Cunningham, K. C., \& Resick, P. A. (2015). Rape survivors' trauma-related beliefs before and after cognitive processing therapy: Associations with PTSD and depression symptoms. Behaviour Research and Therapy, 66, 49-55.

Jaycox, L. H., Zoellner, L., \& Foa, E. B. (2002). Cognitive-behavioral therapy for PTSD in rape survivors. Psychotherapy in Practice, 58, 891-906.

Kessler, R. C., Sonnega, A., Bromet, E., Hughes, M., \& Nelson, C. B. (1995). Posttraumatic stress disorder in the National Comorbidity Survey. Archives of General Psychiatry, 52, 1048-1060.

Koss, M. P., Gidycz, C. A., \& Wisniewski, N. (1987). The scope of rape: incidence and prevalence of sexual aggression and victimization in a national sample of higher education students. Journal of Consulting and Clinical Psychology, 55(2), 162.

Kovacs, M., \& Beck, A. T. (1978). Maladaptive cognitive structures in depression. American Journal of Psychiatry, 135, 525-533.

Larimer, M., Lydum, A., Anderson, B., \& Turner, A. (1999). Male and female recipients of unwanted sexual contact in a college student sample: Prevalence rates, alcohol use, and depression symptoms. Sex Roles, 40, 295-308.

Mezey, G. C., \& King, M. B. (2000). Male victims of sexual assault. Oxford, UK: Oxford University Press.

Mussweiler, T., \& Forster, J. (2000). The sex-aggression link: A perception-behavior dissociation. Journal of Personality and Social Psychology, 79, 507-520.

Najdowski, C. J., \& Ullman, S. E. (2009). PTSD and self-rated recovery among adult sexual assault survivors: The effects of traumatic life events and psychosocial variables. Psychology of Women Quarterly, 33, 43-53.

O'Sullivan, L. F., Byers, E. S., \& Finkelman, L. (1998). A comparison of male and female college students' experiences of sexual coercion. Psychology of Women Quarterly, 22, 177-195. 
Palmer, R. S., McMahon, T. J., Rounsaville, B. J., \& Ball, S. A. (2010). Coercive sexual experiences, protective behavioral strategies, alcohol expectancies and consumption among male and female college students. Journal of Interpersonal Violence, 25, 1563-1578.

Pleck, J. H. (1981). The myth of masculinity. Cambridge, MA: The MIT Press.

Reilly, M. E., Lott, B., Caldwell, D., \& DeLuca, L. (1992). Tolerance for sexual harassment related to self-reported sexual victimization. Gender \& Society, 6 , 122-138.

Resick, P. A., Williams, L. F., Suvak, M. K., Monson, C. M., \& Gradus, J. L. (2012). Long-term outcomes of cognitive-behavioral treatments for posttraumatic stress disorder among female rape survivors. Journal of Consulting and Clinical Psychology, 80, 201-210.

Rosenthal, L., Levy, S. R., \& Earnshaw, V. A. (2012). Social dominance orientation relates to believing men should dominate sexually, sexual self-efficacy, and taking free female condoms among undergraduate women and men. Sex Roles, 67, 659-669.

Solomon, S. D., \& Davidson, J. R. (1997). Trauma: Prevalence, impairment, service use, and cost. Journal of Clinical Psychiatry, 58, 5-11.

Testa, M., Hoffman, J. H., \& Livingston, J. A. (2010). Alcohol and sexual risk behaviors as mediators of the sexual victimization-revictimization relationship. Journal of Consulting and Clinical Psychology, 78(2), 249.

Testa, M., VanZile-Tamsen, C., Livingston, J. A., \& Koss, M. P. (2004). Assessing women's experiences of sexual aggression using the Sexual Experiences Survey: Evidence for validity and implications for research. Psychology of Women Quarterly, 28(3), 256-265.

Tolin, D. F., \& Foa, E. B. (2006). Sex differences in trauma and posttraumatic stress disorder: A quantitative review of 25 years of research. Psychological Bulletin, 132, 959-992. doi:10.1037/0033-2909.132.6.959

Weathers, F. W., Huska, J. A., \& Keane, T. M. (1991). The PTSD Checklist-Civilian Version $(P C L-C)$. Boston, MA: F. W. Weathers, National Center for PTSD, Boston Veterans Affairs Medical Center.

Weathers, F., Litz, B., Herman, D., Huska, J., \& Keane, T. (1993, October). The PTSD Checklist (PCL): Reliability, Validity, and Diagnostic Utility. Paper presented at the Annual Convention of the International Society for Traumatic Stress Studies, San Antonio, $T X$.

Zurbriggen, E. L. (2000). Social motives and cognitive power/sex associations: Predictors of aggressive sexual behavior. Journal of Personality and Social Psychology, 78, 559-581.

\section{Author Biographies}

Daniel J. Snipes, MS, is a doctoral candidate in health psychology at Virginia Commonwealth University. His research interests include sexual violence and rape, substance use, and high-risk sexual behavior. 
Jenna M. Calton, MA, is a clinical psychology doctoral student at George Mason University. Her research interests include trauma and posttraumatic stress in marginalized populations.

Brooke A. Green, MS, is a counseling psychology graduate student at Virginia Commonwealth University. Her research interests include substance use and trauma.

Paul B. Perrin is an assistant professor of psychology at Virginia Commonwealth University, and he received his $\mathrm{PhD}$ in counseling psychology from the University of Florida. He researches multicultural health psychology, and his primary career goal is to use psychology as a vehicle to work toward social justice against different forms of oppression such as racism, heterosexism, and sexism as they manifest themselves in various social systems, especially within the health care system.

Eric G. Benotsch, $\mathrm{PhD}$, is an associate professor of psychology and director of the Health Psychology Doctoral Training Program at Virginia Commonwealth University. His research interests include substance use and HIV prevention. He received his doctoral degree in clinical health psychology from The University of Iowa. 